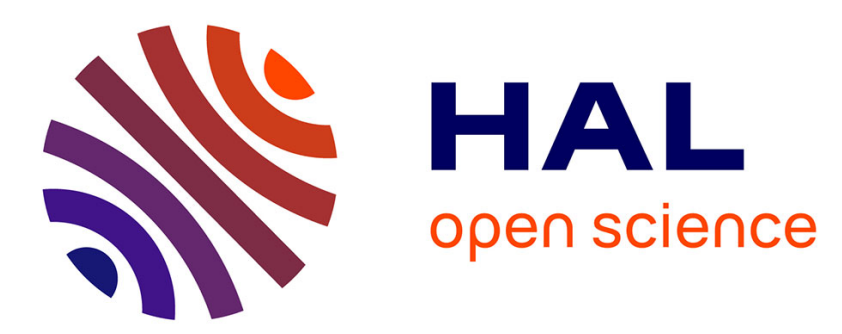

\title{
Green and controlled synthesis of short diol oligomers from polyhydroxyalkanoate to develop fully biobased thermoplastics
}

\author{
Sophie Wendels, Benoît Heinrich, Bertrand Donnio, Luc Avérous
}

\section{To cite this version:}

Sophie Wendels, Benoît Heinrich, Bertrand Donnio, Luc Avérous. Green and controlled synthesis of short diol oligomers from polyhydroxyalkanoate to develop fully biobased thermoplastics. European Polymer Journal, 2021, 153, pp.110531. 10.1016/j.eurpolymj.2021.110531 . hal-03407938

\author{
HAL Id: hal-03407938 \\ https://hal.science/hal-03407938
}

Submitted on 28 Oct 2021

HAL is a multi-disciplinary open access archive for the deposit and dissemination of scientific research documents, whether they are published or not. The documents may come from teaching and research institutions in France or abroad, or from public or private research centers.
L'archive ouverte pluridisciplinaire HAL, est destinée au dépôt et à la diffusion de documents scientifiques de niveau recherche, publiés ou non, émanant des établissements d'enseignement et de recherche français ou étrangers, des laboratoires publics ou privés. 


\title{
Green and controlled synthesis of short diol oligomers from polyhydroxyalkanoate to develop fully biobased thermoplastics
}

\author{
Sophie Wendels ${ }^{a}$, Benoît Heinrich ${ }^{b}$, Bertrand Donnio ${ }^{b}$, Luc Avérous ${ }^{a, *}$ \\ ${ }^{a}$ BioTeam/ICPEES-ECPM, UMR CNRS 7515, Université de Strasbourg, 25 rue Becquerel, 67087 \\ Strasbourg Cedex 2, France. Corresponding author E-mail address: luc.averous@unistra.fr (L. \\ Avérous). \\ ${ }^{\mathrm{b}}$ Institut de Physique et Chimie des Mat'eriaux de Strasbourg (IPCMS), UMR 7504 (CNRS-Universit'e \\ de Strasbourg), 23 rue du Loess, BP 43, 67034 Strasbourg Cedex 2, France
}

Cite as Eur. Polym. J. 2021, 153, 110531

Publication Date: May 18, 2021

https://doi.org/10.1016/i.eurpolymj.2021.110531

\section{Highlights}

- Oligomers based on PHB-diols with controlled molar mass successfully elaborated.

-Very short oligomers based on PHB-diols elaborated with a new green approach.

-PHB-based molecules used as a platform building block for polymers synthesis.

-Fully biobased thermoplastic polyurethanes were prepared and characterized.

- Large range of properties from conventional thermoplastics to elastomers.

Keywords: Biobased, Fatty acid-derived diisocyanate, Poly(3-hydroxybutyrate) oligomers, Sustainability, Thermoplastic polyurethane

\section{Graphical abstract}

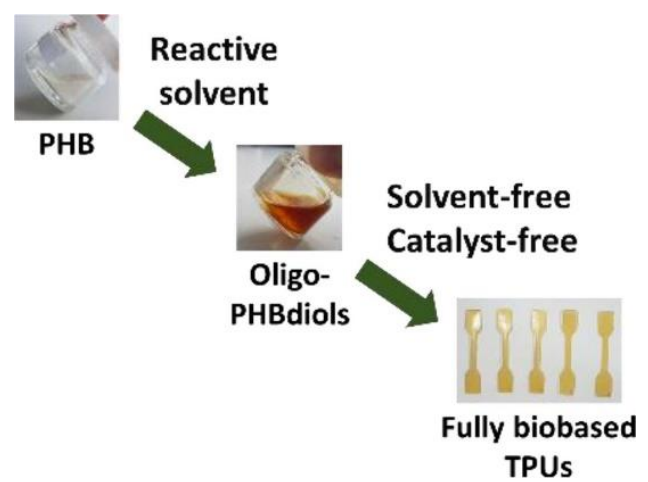

An environmentally friendly reactive solvent method for the preparation of short-chains PHB diol oligomers as new biobased building blocks for renewable macromolecular architectures synthesis.

Abstract: Polyhydroxyalkanoates (PHAs) are a biodegradable and biobased family of bacterial polyesters with different architectures. Among them, the poly-3-hydroxybutyrate (PHB) is one of the most conventional and easily obtained by biotechnologies from different bioresources. However, this thermoplastic polyester known since more than 50 years presents until now only very limited 
applications due to a certain number of drawbacks such as poor mechanical properties, high degree of crystallinity, and low thermal stability. One major way to valorize this bacterial polyester could be to develop controlled building blocks for the synthesis of new generation of biobased polymers. In this way, short linear PHB diols oligomers (oligoPHB-diol) with controlled low molar masses have been successfully obtained from a new synthetic pathway using reactive solvents in a green way. Different transesterification reaction parameters were investigated to control the PHB molar mass decrease, such as the catalyst and reactive solvent contents, the temperature and the reactive solvent type. Obtained oligomers were then analyzed in detail and further incorporated into fully biobased thermoplastics. In this work, thermoplastic polyurethanes (TPU) were elaborated as an example of second-generation biobased thermoplastics. To obtain TPUs with high biobased content, a dimer fatty acid-based diisocyanate, the dimeryl diisocyanate, and another biobased diol, the isosorbide, were used. Two series of TPUs were prepared with (i) varying the isosorbide/oligoPHB-diol ratio, and (ii) different oligoPHB-diol molar mass. Materials were fully evaluated for their structural, thermal and mechanical properties, as well as their crystalline behavior. A large range of properties were obtained for these innovative thermoplastics which could open a large range of applications with a green and sustainable approach.

\section{Introduction}

As a result of increased global concern regarding growing amounts of plastic waste over the last decades, recyclability, controlled degradability and green processes are nowadays crucial. To answer to these concerns, environmentally friendly processes and materials are currently largely developed in the labs and at industrial scales. Biobased materials have gained substantial interests, mainly due to their reduced carbon footprint, but also because they offer new properties compared to conventional fossil-based materials [1]. In this way, different biopolymers can be directly extracted from biomass, such as polysaccharides or proteins, or produced by microorganisms by white technology such as bacterial polymers. Besides, there is an increasing production of biobased polymers with the development of new macromolecular architectures starting from renewable building blocks [2].

Among the currently developed biopolymers, Polyhydroxyalkanoates (PHAs) is a family of biopolyesters synthesized by fermentation by a wide variety of bacteria [3]. These bacterial biopolyesters exist in varied chain lengths and are classified by the number of carbons in the repetitive units [4]. They are fully biobased, biocompatible and often biodegradable, making them ideal candidates for a large range of biomedical or short-term applications. PHAs exist in homoand copolymers and microbial fermentation can nowadays achieve oligomers with low or medium molar masses as well as high molar mass polyesters [5]. Among them, Poly(3hydroxybutyrate) (P3HB or PHB) was the first PHA discovered and studied [6]. PHB is today more or less commercially available produced by biotechnologies at industrial scale [7]. However, due to its overall high production costs linked also to a low production scale, high rigidity and brittle properties coupled with a high degree of crystallinity, and a problematic low thermal stability [6], [8], PHB presents until now a low development. PHB is often difficult to process since under thermal [9] and/or thermo-mechanical [10] input, PHB is very well known to produce crotonic groups by random chains scission at a temperature close to the melting temperature with a strong molar mass decrease during the thermomechanical processing steps. Besides, such a degradation is catalyzed by several byproducts such as residual proteins from e.g. PHB extraction steps from the microorganisms. But several other compounds act also as degradation catalyzers such as amines or silicates [11]. Then, the corresponding processability windows is very narrow and not very well adapted for large scale developments. These drawbacks have hindered the use of PHB for many industrial purposes. In fact, 
nowadays only very limited applications have been found for PHB compared to other biobased polyesters such as poly(lactic acid) (PLA). PLA has become one of the most widely used biobased polymers [12] and can replace in several applications polypropylene (PP) or poly(ethylene terephthalate) (PET), for instance [13]. In consequence, PLA is nowadays largely available with an increasing production with a decreasing price compared to PHB for instance.

Consequently, research on PHB has been focused on overcoming these drawbacks, for instance by surface modification [14], blending with PLA [12], with other polymers [15] or using plasticizers [16] in order to decrease e.g., the processing temperatures. Another smart and valuable way to valorize PHB could be based on controlled oligomers production as building blocks for the synthesis of new polymer generations [17]. For PHB deconstruction, chemical transesterification has two main advantages such as (i) a strong decrease of the average molar mass and (ii) controlled final chemical structures such as polyols.

Polyurethanes (PUs) are a major family of polymers generally obtained from polyaddition between polyols and polyisocyanates. Based on their annual worldwide production of around 20 million tons and a global market of $\$ 50$ billion (2016), PUs rank 6th among all polymers. They can be found in various forms from rigid or flexible foams to elastomers, coating, adhesives, etc. [18] for a large range of applications including biomedical activities. Although nowadays a large range of biobased polyols structures are used [19], only few renewably sourced polyisocyanates are described [20], and even less are available at industrial scale. Among them, one diisocyanate has drawn attention in the past years, the 2-Heptyl-3,4-bis(9-isocyanatononyl)-1-pentylcyclohexane (DDI). DDI is based on vegetable oils with aliphatic and asymmetric diisocyanate [21]. It is obtained by a Diels-Alder reaction (dimerization) between two fatty acids. DDI presents a limited toxicity compared to other diisocyanates, and bring high flexibility and hydrophobicity linked to pending aliphatic chains.

In a deconstruction-construction approach, we firstly propose a new greener pathway for the preparation of short oligomers of PHB with hydroxyls ending chains (oligoPHB-diol) with controlled chain length, avoiding the use of toxic organic solvents such as e.g. chloroform [22] or bis(2methoxyethyl) ether [17a]. Chemical modification of high molar mass bacterial PHB was performed in reactive solvent conditions using biobased diols such as 1,4-butanediol (BDO), 1,3-propanediol (PDO) and 1,2-ethanediol (Etg). The influence of different transesterification parameters on the oligomers molar masses were analyzed in detail. Secondly, the obtained oligomers were used as building blocks to synthesize fully biobased thermoplastics. In this work, different thermoplastic polyurethanes (TPUs) were elaborated as a clear proof of concept. Series of TPUs were prepared in bulk and without catalyst to follow several principles for a green chemistry. TPUs are synthesized with DDI as diisocyanate and different polyols systems based on varying oligoPHB-diol/biobased isosorbide (ISO) ratios. Final physico-chemical, thermal, mechanical and crystalline properties were investigated in detail.

\section{Experimental section}

\subsection{Materials}

PHB (mass-average molar mass $M_{w}=520,000 \mathrm{~g} \cdot \mathrm{mol}^{-1}$ and Dispersity $(\Theta)$ close to 2, determined by Size Exclusion Chromatography (SEC) with polystyrene (PS) as standards, trade name: PHB L88) was kindly supplied by Biocycle (Brazil) and obtained from bacterial fermentation from sugar-cane byproducts. 2heptyl-3,4-bis(9-isocyanatononyl)-1-pentylcyclohexane, or dimeryl diisocyanate (DDI) was offered by Cognis-BASF (Germany) and isosorbide (ISO, $\mathrm{M}_{\mathrm{n}}=146 \mathrm{~g} \cdot \mathrm{mol}^{-1}, 99,8 \%$, trade name: Polysorb P) from Roquette Frères (France). They were used as received. 1,4-butanediol (BDO) (99\%), 1,3-propanediol 
(PDO) (99\%) and pyridine (HPLC grade, 99,5+\%) were purchased from Alfa Aesar. Tetrahydrofuran (THF) (stabilized with $0.025 \%$ BHT) was purchased from Fisher scientific. Dibutyltin dilaurate (DBTL) (95\%), 1,2-ethanediol (Etg) (anhydrous, 99.8\%), chromium (III) acetyl acetonate $\left(\mathrm{Cr}(\mathrm{acac})_{3}\right) \quad(97 \%), 2$-chloro-4,4,5,5-tetramethyl-1,3,2-dioxaphospholane (ClTMDP) (95\%), cholesterol (>99\%), 2,5-dihydroxybenzoic acid (DHB) (>99\%), deuterated chloroform $\left(\mathrm{CDCl}_{3}\right)$ and molecular sieves $4 \AA$ were purchased from Sigma Aldrich. Petroleum ether was purchased from VWR. PHB, BDO, PDO and Etg were dried in an oven under vacuum at $50^{\circ} \mathrm{C}$ overnight prior to use-THF was dried with $15 \mathrm{wt} \%$ preactivated molecular sieves $4 \AA 24 \mathrm{~h}$ prior to use (molecular sieves activation: $50^{\circ} \mathrm{C}$ in an oven under vacuum, $20 \mathrm{~h}$ ).

\subsection{OligoPHB-diol synthesis}

The typical procedure for the PHB chemical modification into oligoPHB-diols is based on different steps. In a round-bottom flask, the appropriate amount of BDO (from 3000 to $18,000 \mathrm{M}$ equivalent), PDO or Etg were added and heated using an oil bath at $180^{\circ} \mathrm{C}$ with argon flow and magnetically stirred. Then, dried PHB (1 M equivalent) was added and the mixture was stirred until complete dissolution. Once a PHB solution was obtained, temperature was set to reaction temperature $\left(180,165\right.$ or $\left.150{ }^{\circ} \mathrm{C}\right)$. The reaction was started by adding a proper amount of DBTL catalyst (from 0.7 to $2.9 \mathrm{M}$ equivalents), and samples were collected and analyzed by SEC at specific times. At a predetermined time, the reaction mixture was precipitated and washed at least three times with a large volume of petroleum ether to remove the catalyst. OligoPHB-diols were finally recovered since BDO, PDO or Etg were eliminated by distillation at 160, 145 and $130^{\circ} \mathrm{C}$ under reduced pressure for $2 \mathrm{~h}$, respectively.

\subsection{Synthesis of the biobased TPUs}

TPUs were synthesized in a one-step bulk process without catalyst in order to follow several principles for a green chemistry. The overall $\mathrm{NCO} / \mathrm{OH}$ ratio was 1.05 . First, DDI was placed in a flame-dried threenecked round-bottom flask and heated to $75{ }^{\circ} \mathrm{C}$ under an argon flow and with mechanical stirring. Then, the proper amounts of oligoPHB-diol and/or ISO were added. In the case of high molar mass oligoPHB-diol, the oligomers were previously solubilized in dry THF before addition. Moreover, at this temperature a rapid melting of ISO was observed. ATR-FTIR was used to monitor the polymerization until the quasi-complete disappearance of the NCO peak at $2400 \mathrm{~cm}^{-1}$. The mixture was poured in a Teflon mold and allowed to cure overnight at $70^{\circ} \mathrm{C}$, and several more hours at $40^{\circ} \mathrm{C}$ under vacuum for TPUs with high molar mass oligoPHB-diol to remove residual THF. thick films $(1 \pm 0.1 \mathrm{~mm})$ were finally obtained by compression-molding (LabTech Engineering Company Itd) from small TPUs pieces preheated for $7 \mathrm{~min}$ at $120^{\circ} \mathrm{C}$, followed by compression between two plates for $5 \mathrm{~min}$ at $120^{\circ} \mathrm{C}$ at a pressure of 160 bar.

The TPUs were called PHBX-Y, were $X$ corresponds to the oligoPHB-diol molar mass, and $Y$ to the oligoPHB-diol/ISO hydroxyl molar ratio (in \%). For instance, PHB450-25 corresponds to a TPU with $25 \%$ hydroxyls coming from a 450 g.mol ${ }^{-1}$ oligoPHB-diol and $75 \%$ hydroxyls coming from ISO.

\subsection{Characterization techniques}

${ }^{1} \mathrm{H},{ }^{13} \mathrm{C}$, DEPT 135 and COSY -NMR analysis of oligoPHB-diols in $\mathrm{CDCl}_{3}$ were obtained with a Bruker $500 \mathrm{MHz}$ spectrophotometer. Calibration was performed using the $\mathrm{CDCl}_{3}$ chemical shift $\left(\delta_{H}=7.26\right.$ and $\delta_{\mathrm{C}}=77 \mathrm{ppm}$ for ${ }^{1} \mathrm{H}$ and ${ }^{13} \mathrm{C}$, respectively). ${ }^{31} \mathrm{P}$ NMR was obtained on the same spectrophotometer after reaction of a oligoPHB-diol sample with the phosphitylation reagent (Cl-TMDP) following standard protocols [23]. For that, an exact amount of oligoPHB-diol (15-20 mg) was dissolved in $450 \mu \mathrm{L} \mathrm{CDCl}$. Then, $100 \mu \mathrm{L}$ cholesterol solution $\left(0.1 \mathrm{M}\right.$ in a mixture of $\mathrm{CDCl}_{3} /$ pyridine (1/1.6)) containing NMR relaxation agent $\mathrm{Cr}(\mathrm{acac})_{3}$ were added as standard. Finally, $50 \mu \mathrm{L}$ of phosphitylation reagent were 
added. The mixture was stirred at room temperature (RT) for $2 \mathrm{~h}$ before being transferred to an NMR tube.

ATR-FTIR analysis was performed on a Nicolet 380 spectrometer equipped with an attenuated total reflexion (ATR) diamond module. Spectra were collected with 32 scans with a previous background for each sample in the range $4000-500 \mathrm{~cm}^{-1}$.

Average molar mass $(\mathrm{Mn})$ and $Ð$ of PHB transesterification reaction were determined by SEC using a Waters apparatus (Acquity-APC) and THF at $40{ }^{\circ} \mathrm{C}$ as mobile phase $(0.6 \mathrm{~mL} / \mathrm{min}$ ). Three columns (Acquity APC XT $450 \AA 2.5 \mu \mathrm{m} 4.6 \times 150 \mathrm{~mm}, 200$ and 45) were connected. Calibration was performed using linear polystyrene (PS) standards.

MALDI-TOF MS analyses was performed with an Autoflex II TOF/TOF analyzer (Bruker Daltonics) equipped with a nitrogen laser $(5337 \mathrm{~nm})$, using DHB as matrix. FlexAnalysis 3.0 software (Bruker Daltonics) was used to perform scan accumulation and data processing.

Thermal degradation was obtained by Thermogravimetric Analysis (TGA) with a Hi-RES TGA Q5000. The experiment was performed under nitrogen at a $25 \mathrm{~mL} \cdot \mathrm{min}^{-1}$ flow rate and from room temperature to $600{ }^{\circ} \mathrm{C}$ at a rate of $10^{\circ} \mathrm{C} \cdot \mathrm{min}^{-1}$.

Differential scanning calorimetry (DSC) measurements were carried out on a TA Instrument Q 200. 2$3 \mathrm{mg}$ samples were placed in sealed aluminum pans and analyzed under dry nitrogen. All the measurements were performed with an empty aluminum pan as reference. First, the samples were heated from room temperature to $180^{\circ} \mathrm{C}$ at a rate of $10^{\circ} \mathrm{C} \cdot \mathrm{min}^{-1}$ and equilibrated for $2 \mathrm{~min}$ to erase the thermal history. Then, pans were cooled down from 180 to $-70^{\circ} \mathrm{C}$ at a rate of $5^{\circ} \mathrm{C} \cdot \mathrm{min}^{-1}$ and equilibrated for $2 \mathrm{~min}$. Finally, the samples were heated to $180^{\circ} \mathrm{C}$ at a rate of $10^{\circ} \mathrm{C} \cdot \mathrm{min}^{-1}$. Crystallinity (xc) was obtained from Eq. (1):

(1) $x \mathrm{c} \%=(\Delta \mathrm{Hm} / \Delta \mathrm{Hm}(0)) \times 100$

where $\Delta \mathrm{Hm}$ is the measured melting enthalpy, and $\Delta \mathrm{Hm}(0)$ the melting temperature of a $100 \%$ pure crystalline polyester (146 J.mol ${ }^{-1}$ for PHB [24]). Complementary DSC in modulated mode (MDSC) was used for the determination of precise $\mathrm{T}_{\mathrm{g}}$ of the oligoPHB-diols. For that, the pans were cooled down to $-50^{\circ} \mathrm{C}$ and equilibrated for $2 \mathrm{~min}$. Then, the MSDC run was performed in heat-only conditions (amplitude: $1.2^{\circ} \mathrm{C}$; period: $60 \mathrm{~s}$; ramp: $2^{\circ} \mathrm{C} / \mathrm{min}$ ) up to $40^{\circ} \mathrm{C}$.

Dynamic mechanical analyses (DMA) were performed using a TA Instrument Discovery Hybrid Rheometer HR-3 in dynamic mode equipped with rectangular torsion geometry. The temperature range varied from $-60^{\circ} \mathrm{C}$ to $100^{\circ} \mathrm{C}$ at a heating rate of $2^{\circ} \mathrm{C}$. $\mathrm{min}^{-1}$ with $1 \mathrm{~Hz}$ frequency. The strain was of $0.1 \%$.

Uniaxial tensile tests were performed on an Instron 5567H (USA) with a 10kN load cell. Experiments were carried out at room temperature with a constant crosshead speed of $20 \mathrm{~mm} \cdot \mathrm{min}^{-1}$. Sets of five dumbbell-shaped samples with dimensions of approximately $45 \times 5 \times 1 \mathrm{~mm}^{3}$ were tested. Elastic modulus $(E)$, stress at break $\left(\sigma_{\max }\right)$ and elongation at break $\left(\varepsilon_{\max }\right)$ were measured.

SWAXS patterns were obtained with a transmission Guinier-like geometry. A linear focalized monochromatic $\mathrm{Cu} \mathrm{K} \alpha_{1}$ beam $(\lambda=1.5405 \AA$ ) was obtained using a sealed-tube generator $(600 \mathrm{~W})$ equipped with a bent quartz monochromator. In all cases, samples were filled in home-made cells of $1 \mathrm{~mm}$ path. The scattering curves were recorded with a curved Inel CPS120 gas-filled counter and corrected from air scattering contribution. 


\section{Results and discussion}

\subsection{Oligo PHB-diols characterization}

Short oligoPHB-diols were synthesized at $180^{\circ} \mathrm{C}$ by transesterification reaction of high molar mass PHB using biobased reactive solvent, mostly BDO, with DBTL as catalyst. Reduced catalyst concentrations were used compared to previous studies in order to work in a greener way [17a]. Moreover, the transesterification reaction, precipitations and distillation processes could be transposed to higher scales. The transesterification reaction is described in Scheme 1. Obtained chemical structures were checked and confirmed by ${ }^{1} \mathrm{H}$ and ${ }^{13} \mathrm{C}$ NMR, DEPT 135 , COSY and FTIR. The molar masses were determined by SEC in THF.

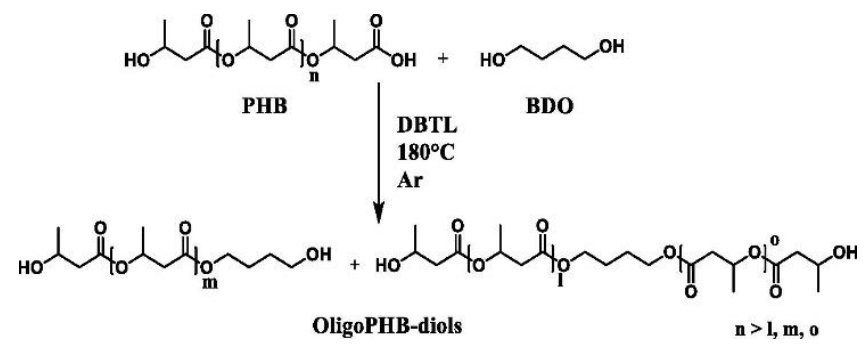

Scheme 1. Transesterification reaction from PHB to oligoPHB-diol.

Only one of the shortest synthesized oligoPHB-diol of around $450 \mathrm{~g} \cdot \mathrm{mol}^{-1}$ (Equivalent to DPn $=3-4$ ) was fully analyzed and presented. The corresponding chemical structure was confirmed by ${ }^{1} \mathrm{H}-,{ }^{13} \mathrm{C}-$ and DEPT 135-NMR. Spectra are presented in Fig. 1a and $\mathrm{b}$ for ${ }^{1} \mathrm{H}$ - and ${ }^{13} \mathrm{C}$ NMR, respectively. DEPT 135- and COSY-NMR are depicted in Supporting Information (SI.1) Characteristic ${ }^{1} \mathrm{H}$ NMR signals for hydroxybutyrate (HB) units were observed at $\delta=5.29,2.44-2.65,1.29 \mathrm{ppm}$ for $-\mathrm{CH}(\mathrm{CH} 3)-\mathrm{CH} 2-\mathrm{CO}-$, $-\mathrm{CH}(\mathrm{CH} 3)-\mathrm{CH} 2-\mathrm{CO}-$ and $-\mathrm{CH}(\mathrm{CH} 3)-\mathrm{CH} 2-\mathrm{CO}-$ protons respectively. Peaks that correspond to oligoPHB-diol primary hydroxyl end-groups were ascribed at $\delta=3.67$ for $\mathrm{HO}-\mathrm{CH} 2-\mathrm{CH} 2-$ protons and secondary hydroxyl end-groups at $\delta=4.19 \mathrm{ppm}$ for $\mathrm{HO}-\mathrm{CH}(\mathrm{CH} 3)-\mathrm{CH} 2-$ protons. Small peaks at chemical shifts $\delta=5.81$ and 6.96 were assigned to the presence of vinyl end-groups due to PHB thermal degradation and formation of crotonyl end-groups and can be seen in the zoomed orange box in Fig. 1. The well-known mechanism of the crotonyl end-groups formation is depicted in scheme 2.

Chemical shifts for ${ }^{13} \mathrm{C}$ NMR at $\delta=170.4,67.6,40.7$, and $19.9 \mathrm{ppm}$ were assigned to $-\mathrm{CH}(\mathrm{CH} 3)-\mathrm{CH} 2-$ $\mathrm{CO}-,-\mathrm{CH}(\mathrm{CH} 3)-\mathrm{CH} 2-\mathrm{CO}-,-\mathrm{CH}(\mathrm{CH} 3)-\mathrm{CH} 2-\mathrm{CO}-$ and $-\mathrm{CH}(\mathrm{CH} 3)-\mathrm{CH} 2-\mathrm{CO}-$ carbons from hydroxybutyrate $(\mathrm{HB})$ repetitive units. Secondary hydroxyl end-groups are represented by peaks at $\delta=172.1,64.3,40.7$, and $19.9 \mathrm{ppm}$ chemical shifts, as depicted in Fig. 1b. They were assigned to $\mathrm{HO}-\mathrm{CH}(\mathrm{CH} 3)-\mathrm{CH} 2-\mathrm{CO}-$ carbons, respectively. Chemical shifts from $\mathrm{HB}$ units next to BDO and primary alcohols are found at $\delta=172.1,64.3,40.7$, and $19.9 \mathrm{ppm}$.

Further analyses from ${ }^{31} \mathrm{P} N M R$ in $\mathrm{CDCl} 3$ with cholesterol as standard were performed and presented in Fig. 1c. Chemical shifts at $\delta=145$ and $147 \mathrm{ppm}$ exhibited the terminal primary and secondary hydroxyl groups from oligoPHB-diol, respectively. No carboxylic acid end-groups were found at a chemical shift $\delta=135$, proving the efficient BDO esterification and transesterification from PHB.

FTIR-ATR spectra of PHB and different synthesized oligoPHB-diols of 450, 700 and 1800 g.mol ${ }^{-1}$ molar masses, respectively, are displayed in Fig. 2. Characteristic peaks from oligoPHB-diol structure were ascribed at $3400,1720,1450,1376,1172$ and $1054 \mathrm{~cm}^{-1}$ corresponding to $\mathrm{O}-\mathrm{H}$ intermolecular stretching vibration, $\mathrm{C}=\mathrm{O}$ from ester groups stretching vibration, methyl $\mathrm{C}-\mathrm{H}$ bending vibration, $\mathrm{O}-\mathrm{H}$ bending vibration, $\mathrm{C}-\mathrm{O}$ from ester groups stretching and terminal hydroxyl $\mathrm{C}-\mathrm{O}$ 
stretching vibration superimposed with $\mathrm{C}-\mathrm{O}-\mathrm{C}$ stretching from ester, respectively. Small peak intensities of cis-disubstituted $\mathrm{C}=\mathrm{C}$ characteristic stretching vibration and its corresponding $\mathrm{C}-\mathrm{H}$ bending vibration were also found at $1655 \mathrm{~cm}^{-1}$ and $735 \mathrm{~cm}^{-1}$, respectively.

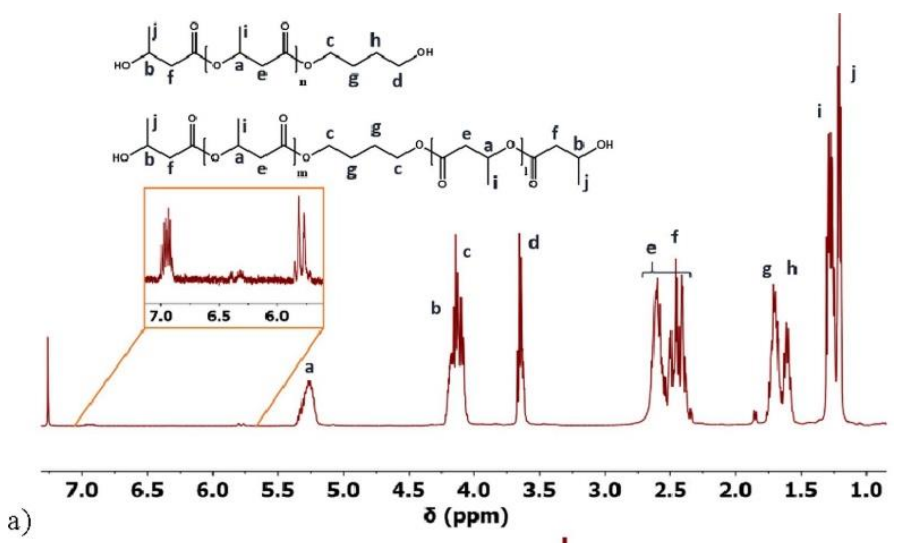

a)
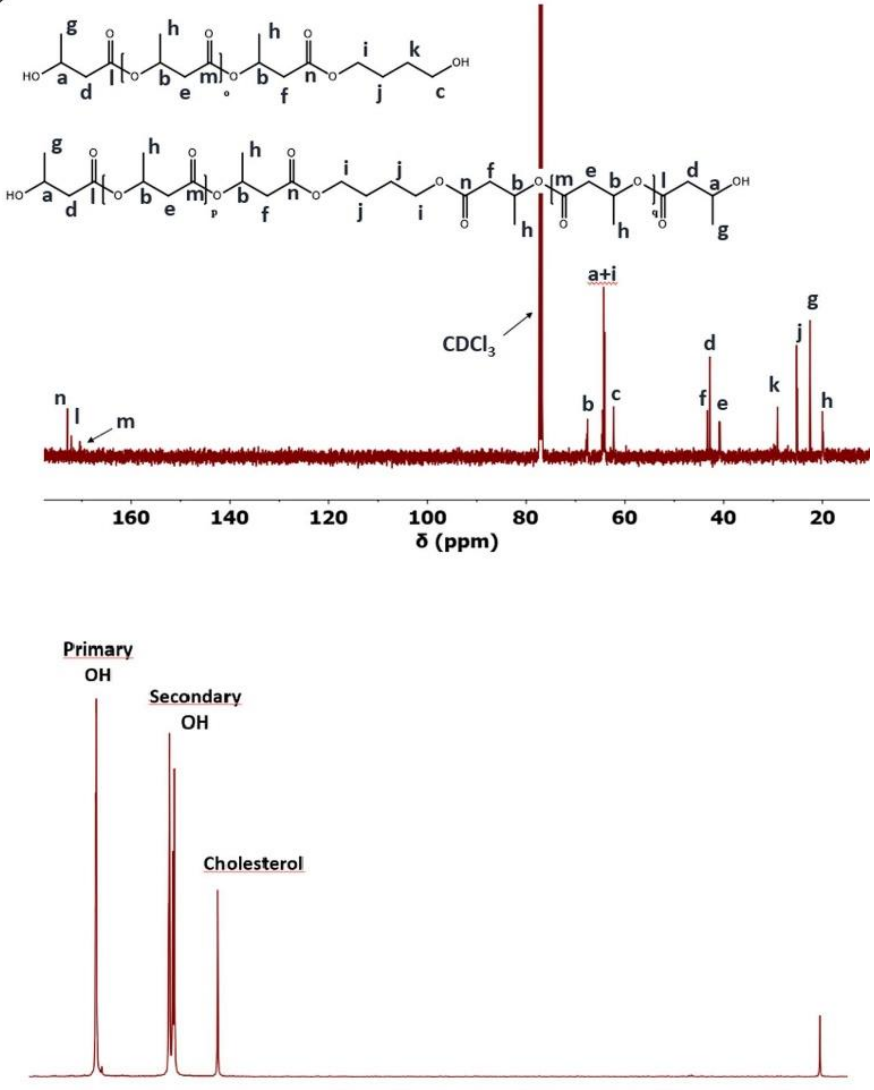

c)

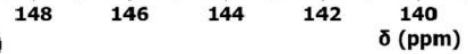

Fig. 1. a) ${ }^{1} \mathrm{H}$, b) ${ }^{13} \mathrm{C}$ and c) ${ }^{31} \mathrm{P}$ NMR spectra of $450 \mathrm{~g} \cdot \mathrm{mol}^{-1}$ oligoPHB-diol in $\mathrm{CDCl}_{3}$.

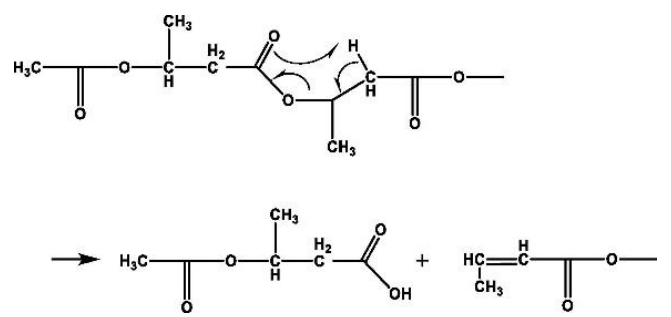

Scheme 2. Reaction mechanism of crotonyl end-group formation by PHB random chain scission. 


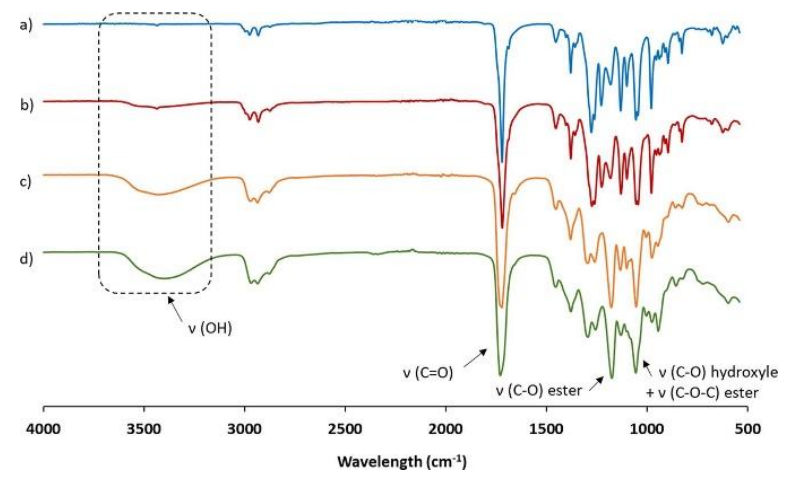

Fig. 2. FTIR spectra of a) PHB, and oligoPHB-diols of various $\mathrm{Mn}$, b) $1800 \mathrm{~g} \cdot \mathrm{mol}^{-1}$, c) $700 \mathrm{~g} \cdot \mathrm{mol}^{-1} \mathrm{I}$ and d) 450 g.mol ${ }^{-1}$.

The oligoPHB-diol was further analyzed by MALDI-TOF MS and the corresponding spectrum is represented in Fig. 3. Two main oligomeric species were observed with either hydroxyl-hydroxyl endgroups or vinyl-hydroxyl end-groups, the greatest intensity corresponding to hydroxyl-hydroxyl endgroups. These observations are on agreement with the previous presented results from ${ }^{1} \mathrm{H} N M R$ and FTIR of the oligoPHB-diol.

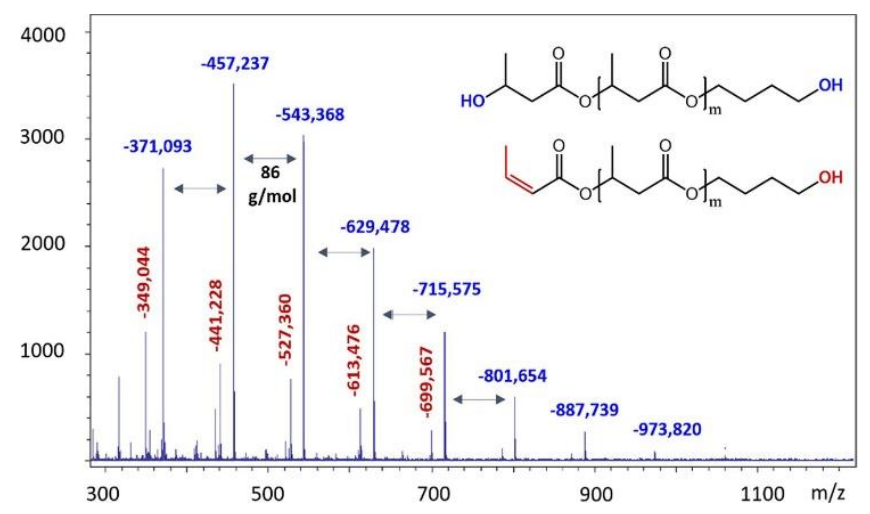

Fig. 3. 450 g. $\mathrm{mol}^{-1}$ oligoPHB-diol MALDI-TOF MS spectrum with peak interpretation.

\subsection{Influence of the reaction parameters to control the molar masses of the oligoPHB-diols}

The influence of the main reaction parameters (temperature, DBTL molar equivalent, BDO molar ratio, diol molecule) on $M_{n}$ were analyzed and further discussed. For that, oligoPHB-diol $M_{n}$ over time was followed by SEC in THF and results are plotted in Fig. 4. $\oplus$ evolutions are displayed in Supporting Information (SI.2). For all reactions, molar mass and $Ð$ decreased drastically during the first hour of reaction until reaching a plateau corresponding to a mixture of two building blocks as shown in Scheme $\underline{1}$, with $\mathrm{l}, \mathrm{m}$ and o equal to 0 , respectively. For $\emptyset$ evolution, a plateau is reached at a value close to 1 . All reactions followed the same inverse-exponential plot shape. As expected, $M_{n}$ decreased with the increase of catalyst amount from 0.7 to $2.9 \mathrm{M}$ equivalent. Moreover, for each tested catalyst content, the obtained molar mass was lower than $1000 \mathrm{~g} \cdot \mathrm{mol}^{-1}$ after only 30 min reaction.

However, for $0.7 \mathrm{M}$ equivalents, acid end-groups were still found in the polymer, as depicted in Supporting Information (SI.3) in the ${ }^{31} \mathrm{P}$ NMR spectra. Since $1.5 \mathrm{M}$ equivalent demonstrates a too slow reaction, $2.2 \mathrm{M}$ equivalent was found to be the most suitable content to obtain oligomers with hydroxyl end-groups within few hours. 

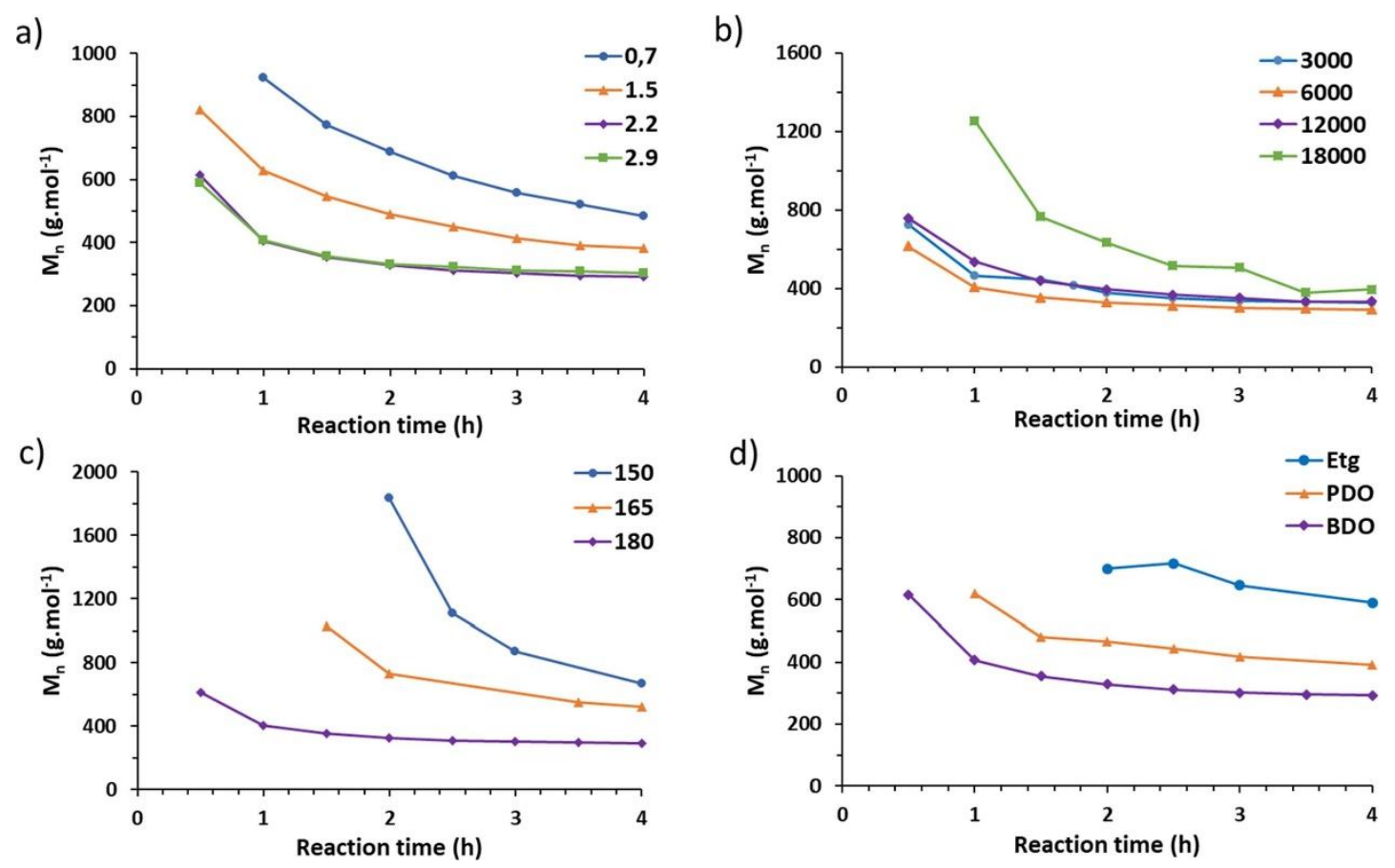

Fig. 4. OligoPHB-diols $\mathrm{Mn}$ decrease over time with a) $\mathrm{DBTL}$ molar equivalents, $\mathrm{T}=180^{\circ} \mathrm{C}$ and $6000 \mathrm{M}$ equivalent $\mathrm{BDO}, \mathrm{b}) \mathrm{BDO}$ molar equivalents, $\mathrm{T}=180^{\circ} \mathrm{C}$ and $2.2 \mathrm{M}$ equivalents $\mathrm{DBTL}, \mathrm{c}$ ) temperature, with $2.2 \mathrm{M}$ equivalent $\mathrm{DBTL}$ and $6000 \mathrm{M}$ equivalents $\mathrm{BDO}$, d) short diol length, $\mathrm{T}=180^{\circ} \mathrm{C}, 2.2 \mathrm{M}$ equivalent $\mathrm{DBTL}$ with $6000 \mathrm{M}$ equivalents.

Increasing BDO excess from 3000 to 18,000 M equivalents however did not affect $\mathrm{M}_{\mathrm{n}}$ of the oligomers. With high BDO molar equivalents (18000), the molar mass decrease was slightly lower than for the others tested systems. It might be due to the catalyst dilution in the reaction medium. On the contrary, with 3000 equivalents the reaction mixture was highly viscous when PHB was melting in the BDO. Finally, $6000 \mathrm{M}$ equivalents were the best compromise for a good mixing and in a green approach to avoid overuse of reactive solvent. Anyway, the distillation of the excess short diol could be recycled for further oligoPHB-diol preparation, for instance.

The dependency of the reaction temperature on reaction time is obvious. At low temperature $\left(150^{\circ} \mathrm{C}\right)$ the reaction reached $700 \mathrm{~g} \cdot \mathrm{mol}^{-1}$ after $4 \mathrm{~h}$ reaction, while the same $\mathrm{M}_{\mathrm{n}}$ was obtained after only 2 and $0.5 \mathrm{~h}$ at 165 and $180^{\circ} \mathrm{C}$, respectively. Since $\mathrm{T}_{\mathrm{m}}$ of PHA is $175-177^{\circ} \mathrm{C}$, it was first melted in BDO at $180^{\circ} \mathrm{C}$ prior to set the reaction temperature $\left(165\right.$ or $\left.150^{\circ} \mathrm{C}\right)$ and before the catalyst addition. These supplementary steps and the high increase in reaction time were not suitable to get fast and environmentally friendly oligomers preparation. After some preliminary tests, a temperature of $180^{\circ} \mathrm{C}$ was chosen to optimize short oligoPHB-diol formation.

In contrary to results from previous studies [25], the short diol used as reactive solvent had an influence on the overall $M_{n}$ decrease (Fig. 4d)). The longer the diol chain (from Etg to BDO), the greater the molar mass decrease over time. This was probably due to a higher chain mobility with BDO than with PDO and Etg.

By decreasing the oligoPHB-diol molar mass, the physical aspect of the oligomers varies from white powdery solids as PHB, to brownish viscous liquids below $1000 \mathrm{~g} \cdot \mathrm{mol}^{-1}$. Moreover, the oligomers viscosity decreased with the molar mass, as depicted in Table 1. oligoPHB-diols with low viscosities present a great advantage for bulk process, to avoid the use of toxic and environmentally unfriendly organic solvents, with a green chemistry approach. The corresponding color change was attributed to 
some partial thermal degradation of PHB due to the high temperature resulting in crotonyl end-groups

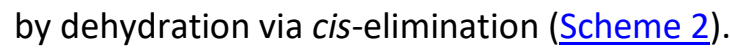

Table 1. Physico-chemical and thermal properties of different $M_{n}$ oligoPHB-diol.

\begin{tabular}{|c|c|c|c|c|c|c|c|}
\hline OligoPHB-diol $\mathrm{Mn}_{\mathrm{n}}$ & $\mathrm{T}_{5 \%}\left[{ }^{\circ} \mathrm{C}\right]$ & $\mathrm{T}_{\mathrm{deg}, \max }\left[{ }^{\circ} \mathrm{C}\right]$ & $\mathrm{Tg}_{\mathrm{g}}\left[{ }^{\circ} \mathrm{C}\right]$ & $\mathrm{T}_{\mathrm{m}}\left[{ }^{\circ} \mathrm{C}\right]$ & $\mathrm{T}_{\mathrm{c}}\left[{ }^{\circ} \mathrm{C}\right]$ & $x[\%]$ & Viscosity $\left(25^{\circ} \mathrm{C}\right)[\mathrm{Pa} . \mathrm{s}]$ \\
\hline 260000 g. mol ${ }^{-1}$ & 270 & 290 & n.v & 172 & 111 & 57 & - \\
\hline $1800 \mathrm{~g} \cdot \mathrm{mol}^{-1}$ & 245 & 283 & -11 & 140 & 70 & 57 & - \\
\hline $700 \mathrm{~g} \cdot \mathrm{mol}^{-1}$ & 182 & 265 & -17 & 109 & 77 & 17 & $30640 \pm 1261$ \\
\hline $450 \mathrm{~g} \cdot \mathrm{mol}^{-1}$ & 137 & 236 & -17 & - & - & - & $1.62 \pm 0$ \\
\hline
\end{tabular}

Thermal properties of the oligoPHB-diols were further investigated by TGA and DSC. TGA and corresponding DTG curves are presented in Fig. 5. DSC curves are presented in Supporting Information (SI.4) and main data are summarized in Table 1. As already observed in previous studies [25], PHB degraded in one step while oligoPHB-diols had a two- steps degradation process, as depicted in the DTG curves. This is due to a consequent loss of ester bonds and the corresponding hydrogen bonding strength, the onset temperatures that led to a $5 \mathrm{wt} \%$ weight loss $\left(T_{5 \%}\right)$ and the maximum degradation rate temperature $\left(T_{\text {deg,max }}\right)$ clearly decreased with the oligoPHB-diol molar mass. A lower thermal stability was observed for $450 \mathrm{~g} \cdot \mathrm{mol}^{-1}$ oligoPHB-diol with a low $\mathrm{T}_{5 \%}$ of $137^{\circ} \mathrm{C}$ and a $T_{\text {deg, max }}$ at $236^{\circ} \mathrm{C}$. With regard to DSC results, $T_{\mathrm{g}}$ were observed for oligoPHB-diols but not for PHB. Moreover, $T_{g}$ decreased with decreasing oligoPHB-diol $\mathrm{M}_{\mathrm{n}}$, up to $-17^{\circ} \mathrm{C}$ for 700 and $450 \mathrm{~g} \cdot \mathrm{mol}^{-1}$. Decreasing $\mathrm{T}_{\mathrm{m}}$ were also observed from PHB to oligoPHB-diol $700 \mathrm{~g} \cdot \mathrm{mol}^{-1}$, which is correlated to a loss of crystallinity from a lower ester bonds amounts and specific oligoester organization.

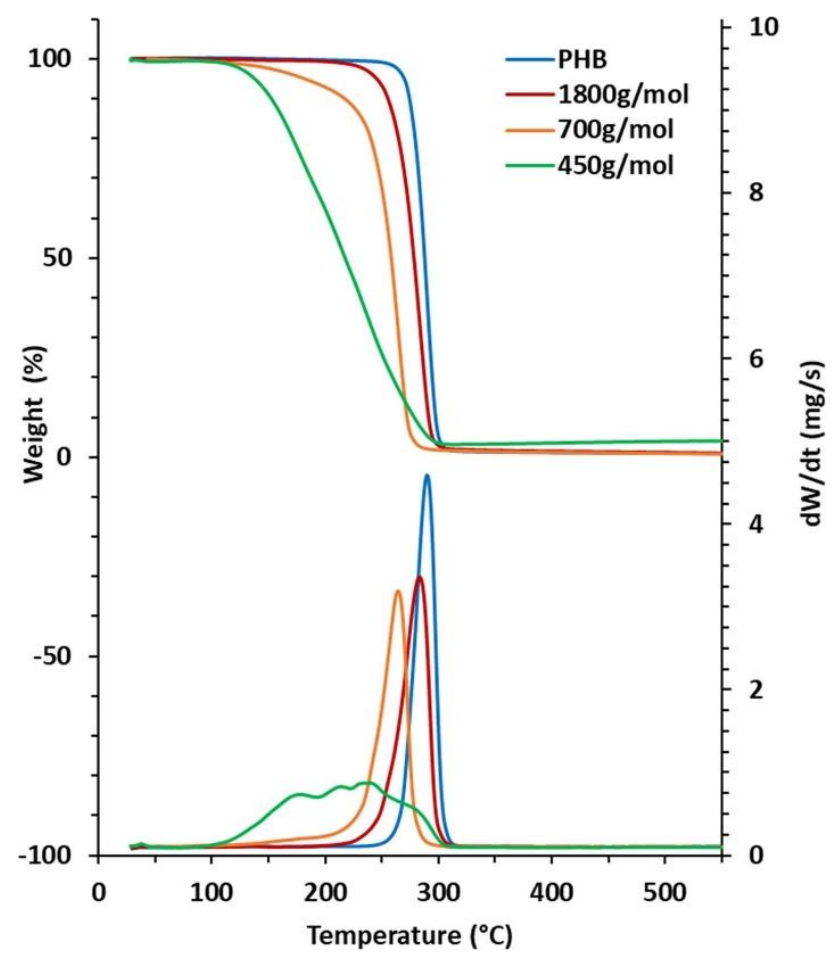

Fig. 5. TGA spectra of initial PHB and different oligoPHB-diols with varying $\mathrm{Mn}_{\mathrm{n}}$. 


\subsection{Synthesis and characterization of biobased TPUs from oligoPHB-diols}

Environmentally friendly and fully biobased TPUs were further prepared as proof of concept for the valorization of oligoPHB-diols. The formulations comprised DDI and different oligoPHB-diol $M_{n}$, as well as decreasing ISO content i.e., decreasing the hard segment (HS) or increasing the soft segment (SS) content. The syntheses were carried out in one step at $75{ }^{\circ} \mathrm{C}$ without organic solvent or catalyst. In the case of PHB1800-50, the oligoPHB-diol was first dissolved in a minimum of dried THF, before addition during the synthesis. Resulting chemical structures of the materials were analyzed and confirmed by FTIR. The different TPUs formulations and abbreviations are listed in Table 2. The chemical structures of the three main components are depicted in Fig. 6.

Table 2. TPUs compositions (mol\% are in brackets).

\begin{tabular}{lllll}
\hline TPU name & $\begin{array}{l}\text { Isosorbide content } \\
{[w t \%]}\end{array}$ & $\begin{array}{l}\text { OligoPHB-diol content } \\
{[\text { wt\%] }}\end{array}$ & $\begin{array}{l}\text { DDI content } \\
{[w+\%]}\end{array}$ & $\begin{array}{l}\text { OligoPHB-diol } \\
\mathbf{M}_{\mathrm{n}}\left[\mathrm{g} \cdot \mathrm{mol}^{-1} \text { ] }\right.\end{array}$ \\
\hline PHB450-0 & $16.5(50)$ & $0(0)$ & $83.5(50)$ & 460 \\
PHB450-25 & $11.8(37.5)$ & $8.3(12.5)$ & $79.9(50)$ & 460 \\
PHB450-50 & $7.5(25)$ & $15.9(25)$ & $76.6(50)$ & 460 \\
PHB450-75 & $3.6(12.5)$ & $22.9(37.5)$ & $73.5(50)$ & 460 \\
PHB450-100 & $0(0)$ & $29.3(50)$ & $70.7(50)$ & 460 \\
PHB700-50 & $6.2(25)$ & $31.3(25)$ & $62.5(50)$ & 715 \\
PHB1800-50 & $4.2(25)$ & $52.8(25)$ & $43.0(50)$ & 1800
\end{tabular}

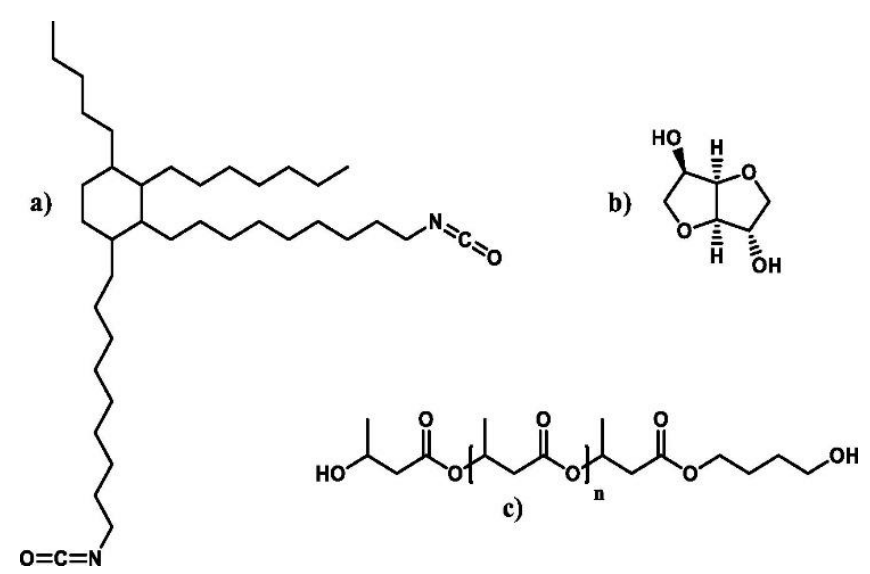

Fig. 6. Main chemical structures for TPU synthesis: a) DDI, b) ISO and c) oligoPHB-diol.

FTIR-ATR was used to control the completion of the polyaddition reaction between the isocyanates and the hydroxyls groups from the oligoPHB or from the ISO. Characteristic NCO stretching band disappearance at $2260 \mathrm{~cm}^{-1}$ was followed during the reaction until complete disappearance. Final TPUs spectra are displayed in Supporting Information (SI.5). Characteristic bands appearance at $3330,1700,1535$ and $1250 \mathrm{~cm}^{-1}$ for $\mathrm{N}-\mathrm{H}$ stretching vibration, urethane $\mathrm{C}=\mathrm{O}$ stretching vibration, $\mathrm{N}-\mathrm{H}$ bending vibration and $\mathrm{C}-\mathrm{O}$ stretching vibration respectively were observed, as well as $\mathrm{O}-\mathrm{H}$ stretching vibration disappearance from oligo PHB-diol. $\mathrm{C}=\mathrm{O}$ stretching vibrations shifting to higher wavenumbers and its broadening with higher oligoPHB-diol content is in accordance with the addition of more ester bonds in the final TPU architecture. Same conclusions can be drawn with oligoPHB-diol 
molar mass increase: higher molar mass resulted in a higher number of $\mathrm{HB}$ repetitive units, and then, ester bonds. Moreover, other characteristic bands from oligoPHB-diol at 1172 and $1054 \mathrm{~cm}^{-1}$ appeared and their intensities increased with higher oligoPHB-diol contents and $\mathrm{M}_{\mathrm{n}}$. At the same time, characteristic cyclic isosorbide $-\mathrm{CH}_{2}$ - absorption band at $1094 \mathrm{~cm}^{-1}$ decreased with lower isosorbide content. Slight $\mathrm{N}-\mathrm{H}$ bending vibration band shifts to smaller wavenumbers from 1540 to $1527 \mathrm{~cm}^{-1}$ were also observed and attributed to the gradual replacement of ISO by oligoPHB-diol moieties.

Small and Wide Angle X-ray Scattering SAXS-WAXS (SWAXS) patterns are shown in Fig. 7. Raw measurements are summarized in Table 3. DDI has been reported to form amorphous urethane-based domains with low $\mathrm{T}_{\mathrm{g}}$ [26]. Accordingly, all polymers give patterns with broad scattering signals in the small- and wide-angle regions, demonstrating an amorphous, phase-separated polymer. Fig. 7a exhibits SWAXS patterns for increasing oligoPHB-diol/ISO ratios. Specifically, the scattering maximum at $1.4 \AA^{-1}$ results from lateral distances between segments $h$ higher than $4.50 \AA$ and those at $0.19 \AA$ from average distances between domains i.e. from long periods $L$ ranging from 32 to $34 \AA$. The type of phase-separated structure depends on intrinsic segments properties such as the soft/hard character related to thermal properties. In PHB450-0 polymer, ISO is a HS self-assembling in domains with urethane groups, while the aliphatic part of DDI forms intermediate SS phases. The HS domain thickness i.e. the short period $S$ can be obtained from scattering profile using the one-dimensional correlation function [27] and is found to be 11-12 Å as for previously reported DDI:ISO polymers [28]. Contrarily to former works on PHB-diol-based polymers [25], [29], the $450 \mathrm{~g} \cdot \mathrm{mol}^{-1}$ oligoPHB-diol is here as a low molar mass building block acting as a HS. The configuration of the phase-separation in domains is therefore equivalent for PHB450-100 and PHB450-0. One notes the closeness of their $L$ and $S$ periods, which implies that PHB chains adopt tilted/folded conformations to compensate for size differences. Beyond the similarity of structures, the different nature of HS modifies electronic density contrasts and leads to intensity ratio of scattering signals $I_{S A} / I_{W A}$ varying by factor 3-4 between both polymers. For the polymers based on diol mixtures, $I_{S A} / I_{W A}$ values are intermediate and regularly increase with ISO content while shape and position of scattering signals hardly change in the series. Consequently, HS domains of ISO and PHB are intercalated or mixed without significant modification of the overall phase-separated structure.
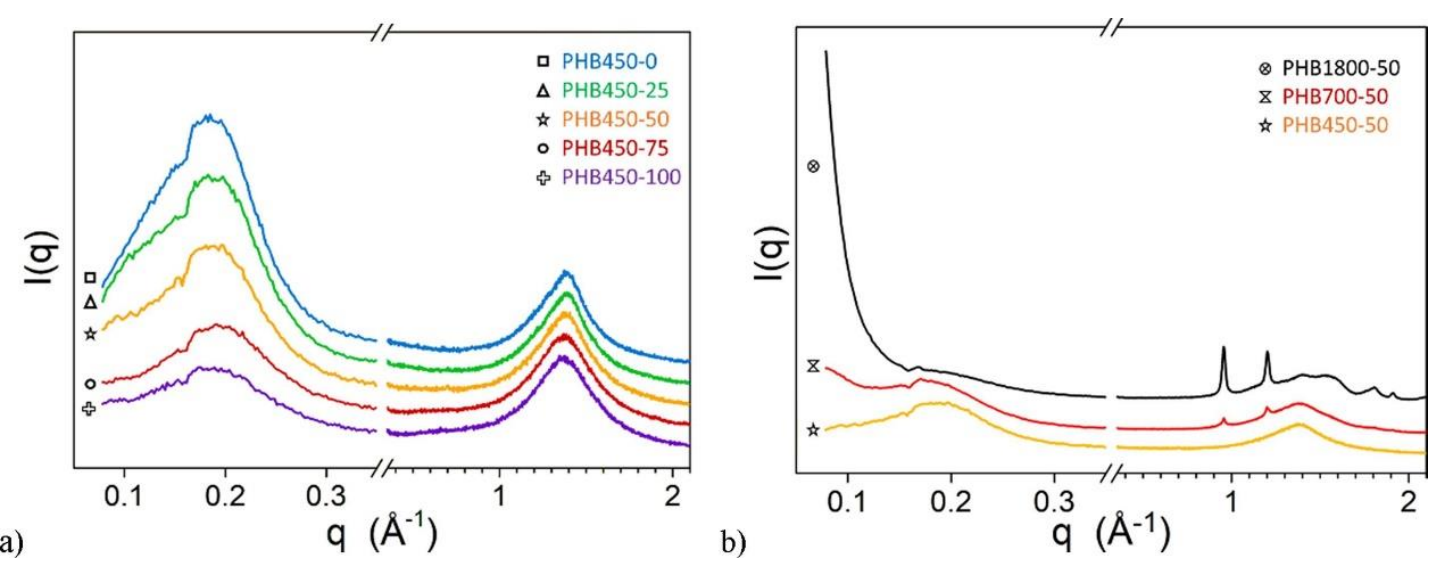

Fig. 7. SWAXS patterns of the TPUs based on DDI with a) various molar proportions of ISO and oligoPHB-diol segments and $b$ ) increasing oligoPHB-diol $\mathrm{Mn}_{\mathrm{n}}$. (Please use color in print). 
Table 3. Raw measurements on scattering curves. See text for definition. Accuracy of $h$ is $0.02 \AA$. Accuracy of $L$ is $0.3 \AA$.

\begin{tabular}{|c|c|c|c|c|}
\hline TPU name & $\mathrm{h}[\mathrm{x}]_{-}^{*}[\AA \mathrm{A}]$ & $L[x][\AA ̊]$ & $S$ [Å] & IsA/IwA [\%] \\
\hline PHB450-0 & $4.54[13]$ & 33.8 [45] & 11.6 & 93 \\
\hline PHB450-25 & 4.54 [13] & $33.6[45]$ & - & 77 \\
\hline PHB450-50 & $4.56[12]$ & 33.5 [45] & - & 54 \\
\hline PHB450-75 & $4.58[11]$ & $32.6[40]$ & - & 31 \\
\hline PHB450-100 & $4.58[11]$ & $33.2[40]$ & 11.1 & 27 \\
\hline PHB700-50 & - & - & - & - \\
\hline PHB1800-50 & - & - & - & - \\
\hline
\end{tabular}

The copolymer with oligoPHB-diol $\mathrm{M}_{n}$ of $450 \mathrm{~g} \cdot \mathrm{mol}^{-1}$ was shown to be amorphous with intercalated ISO and PHB HS domains (mixing cannot be ruled out). With oligoPHB-diols of higher molar masses, as exhibited in Fig. 7, copolymers are semi-crystalline, as demonstrated by the appearance of sharp reflections from crystalline domains in the wide-angle region and of an upturn at very low-angles due to scattering from entire crystallites. In this phase-separated polymer, crystalline domains of PHB therefore alternate with the soft segment phase of DDI and with hard segment domains of ISO. The crystallinity increases with the oligoPHB-diol molar mass, in consistency with the trend reported for other PHB-diol monomers [29].

TPUs thermal properties were further investigated using TGA and DSC. DSC spectra are presented in Fig. 8. TGA and DTG curves are given in Supporting Information (SI.6). Table 4 lists the main results obtained from these curves. The overall degradation takes place in three steps ( $T_{\text {deg1, max, }} T_{\text {deg2, max }}$ and $T_{\text {deg3,max }}$ ). This was mostly due to DDI, which represents a high fraction of the TPU formulations (Table 2). As expected, the onset degradation temperature $\left(T_{5 \%}\right)$ for all TPUs was above $250{ }^{\circ} \mathrm{C}\left(280-300^{\circ} \mathrm{C}\right)$, which corresponds to a good thermal stability. The degradation onset corresponds to the less thermally stable part of the TPUs, which is usually the HS [30]. Here, the first degradation step ( $\left.T_{\text {deg1, max }}\right)$ was associated to $T_{5 \%}$. Hence, $T_{\text {deg1,max }}$ was attributed to urethane degradation or retro-urethanisation, coupled with oligoPHB-diol esters degradation. This is due to the oligoPHB-diol acting as HS, as described earlier in the SWAXS section. There was indeed a decrease in $\mathrm{T}_{\text {deg1, max }}$ with the oligoPHB-diol content as well as molar mass increase, while $T_{\text {deg2, max }}$ and $T_{\text {deg3,max }}$ remained similar for all formulations. The second weight loss at $360-370^{\circ} \mathrm{C}$ was ascribed to fatty acid chain scission from DDI, and the last degradation step at $440-460^{\circ} \mathrm{C}$ is due to the loss of remaining residues from the previous degradations, which is in accordance with previous studies on TPUs using DDI as diisocyanate [31]. 

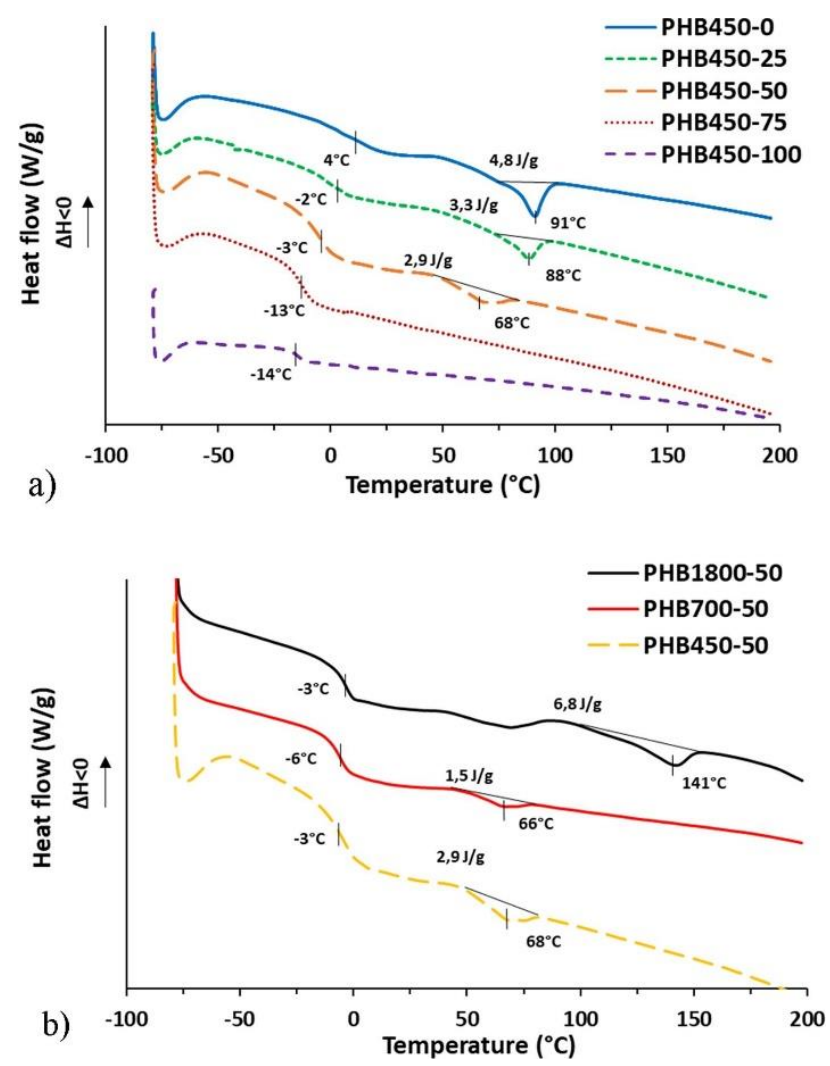

Fig. 8. a) Thermograms of TPUs PHB450-0 to PHB450-100 and b) from TPU PHB450-50 to PHB1800-50.

Table 4. Thermal properties of the biobased TPUs.

\begin{tabular}{|c|c|c|c|c|c|c|c|c|c|}
\hline TPU name & $\begin{array}{l}\text { DSC } \\
\mathrm{Tg}_{\mathrm{g}}\left[{ }^{\circ} \mathrm{C}\right]\end{array}$ & $\begin{array}{l}\mathrm{DMA} \\
\mathrm{T}_{\alpha}\left[{ }^{\circ} \mathrm{C}\right]\end{array}$ & $\begin{array}{l}\text { DSC } \\
T_{m}\left[{ }^{\circ} \mathrm{C}\right]\end{array}$ & $\begin{array}{l}\mathrm{DSC} \\
\mathrm{T}_{\mathrm{c}}\left[{ }^{\circ} \mathrm{C}\right]\end{array}$ & $\Delta \mathrm{H}_{\mathrm{m}}[\mathrm{J} / \mathrm{g}]$ & $\begin{array}{l}\text { TGA } \\
T_{5 \%}\left[{ }^{\circ} \mathrm{C}\right]\end{array}$ & $\mathrm{T}_{\mathrm{deg} 1, \max }\left[{ }^{\circ} \mathrm{C}\right]$ & $\mathrm{T}_{\operatorname{deg} 2, \max }\left[{ }^{\circ} \mathrm{C}\right]$ & $\mathrm{T}_{\mathrm{deg} 3, \max }\left[{ }^{\circ} \mathrm{C}\right]$ \\
\hline PHB450-0 & 4 & 1 & 91 & 55 & 4.8 & 275 & 303 & 368 & 449 \\
\hline PHB450-25 & -2 & 0 & 88 & 49 & 3.3 & 272 & 295 & 364 & 452 \\
\hline PHB450-50 & -3 & -5 & 68 & - & 2.9 & 262 & 290 & 371 & 449 \\
\hline PHB450-75 & -13 & -9 & - & - & - & 262 & 286 & 371 & 449 \\
\hline PHB450-100 & -14 & -13 & - & - & - & 264 & 284 & 367 & 449 \\
\hline PHB700-50 & -6 & -3 & 66 & - & 1.5 & 263 & 286 & 372 & 459 \\
\hline PHB1800-50 & -3 & 3 & 141 & - & 6.8 & 240 & 271 & 367 & 449 \\
\hline
\end{tabular}

TGA curves have shown that in the temperature range of DSC analysis, no major degradations occurred. TPUs thermal transitions are represented in Fig. 8. The TPU without oligoPHB-diol exhibited the highest $\mathrm{T}_{\mathrm{g}}\left(4^{\circ} \mathrm{C}\right)$ and melting point $\left(\mathrm{T}_{\mathrm{m}}=91^{\circ} \mathrm{C}\right)$. This is linked to the cyclic structure of ISO and the HS content increase with stronger urethane bonds, in accordance with previous studies [26], [28]. 
Moreover, TPU melting with high ISO content also presents two steps. This temperature range at melting step can be explained by a gradual melting of the hydrogen-bond urethane layers, as shown in a previous study [27]. Materials comprising 37.5 and 50 mol\% ISO displayed increased melting enthalpies from 3.3 to $4.8 \mathrm{~J} / \mathrm{g}$ due to an increase of crystallinity in the latter. Increasing oligoPHB-diol in the formulation reduced both $\mathrm{T}_{\mathrm{g}}$ and $\mathrm{T}_{\mathrm{m}}$ until getting a material with $\mathrm{T}_{\mathrm{g}}$ around $-14{ }^{\circ} \mathrm{C}$ without $\mathrm{T}_{\mathrm{m}}$ or crystallization step. They are amorphous polymers, as it is sometimes the case for TPUs [32], with $\mathrm{HS} / \mathrm{SS}$ phase separation, as described in the SWAXS pattern (ig. 7). TPUs with increasing oligoPHB-diol molar mass exhibited similar $T_{g}$, but unusual $T_{m}$ behavior: First $T_{m}$ slightly decreased for PHB700-50 from 68 to $66^{\circ} \mathrm{C}$, respectively. Then, $T_{m}$ increased from 66 to $141{ }^{\circ} \mathrm{C}$ for PHB1800-50. Firstly, oligoPHBdiol molar mass increase would primarily enhance the overall flexibility of the TPUs, leading to a decrease both in $T_{g}$ and $T_{m}$, as depicted in Fig. 8 and in Table 4. Then, increasing more the $M_{n}$ would drastically increase the number of ester bonds and the hydrogen bonding between esters and ester bonds with urethane bonds, resulting in a more organized structure and higher $\mathrm{T}_{\mathrm{m}}$.

Dynamic mechanical analysis (DMA) of the biobased TPUs was performed and results are depicted in Fig. 9. A first transition described by a loss of $\mathrm{E}^{\prime}$ and a peak in the tan $\delta$ curve give the relaxation temperature $\left(T_{\alpha}\right)$. T $\alpha$ was taken at the maximum of the peak and given in Table 4 . T $\alpha$ can be usually associated with the Tg determined by DSC. In Table 4, T $\alpha$ determined by DMA were in accordance with $\mathrm{T}_{\mathrm{g}}$ from DSC analysis. It can be observed that the oligoPHB-diol content increase in TPU from PHB4500 to PHB450-100 shifted $T_{\alpha}$ to lower temperatures. The tan $\delta$ peak intensity also reveals amorphous behavior of the polymer. It is understood that the higher the peak intensity, the higher the amorphous phase of the TPU. PHB450-100 and PHB450-75 being fully amorphous displayed the highest peaks. Besides, with increasing amount of ISO, $\tan \delta$ curves peaks depicted a decrease of intensity coupled with a broadening. This phenomenon can be explained by a lower homogeneity of the overall physical crosslinking density in the TPU matrix, which is common in multiphase polymers. Furthermore, a polymerization taking place in one-step presents $\mathrm{HS}$ and SS domains heterogeneities, and thus further lead to inhomogeneous physical crosslinking density. At higher temperatures, the formation of a rubbery plateau was observed from PHB450-50 to PHB450-0 due to the crystalline domains provided by the cyclic ISO, as demonstrated by SWAX analysis. Slight slope change in PHB450-75 revealed some physical crosslink and crystallinity in the TPU. However, it was not considered as a plateau and thus the polymer cannot be described as semi-crystalline which is confirmed by the lack of $T_{m}$ in DSC. The plateau's storage modulus increased with ISO content because of a higher crystallinity degree.

Except for the amorphous PHB450-100, the terminal area after the rubbery plateau was illustrated by another decrease in storage modulus for all TPUs, which was attributed to the disruption of ordered domains. This decrease of storage modulus is interpreted as physical interactions losses between chains and their ability to move, linked to the matrix free volume [33]. The decrease of $E^{\prime}$ in the terminal region seems correlated to the gradual melting transition of TPU based on ISO, also previously shown by DSC. It seems to be noted in PHB450-50 and more particularly in PHB450-25 and PHB450-0. Finally, the apparition of a smaller plateau at high temperatures is due to high physical crosslink in TPUs with high ISO content and its steric hindrance linked to its specific chemical structure. DMA analyses with increasing oligoPHB-diol $\mathrm{M}_{n}$ are depicted in Fig. 9. In the low temperature region, a decrease of tan peak intensity and broadening is also observed, probably due to the synthesis in a onestep process leading to heterogeneous HS and SS domains. Higher degrees of crystallinity with greater molar mass is demonstrated by an increased rubbery plateau's storage modulus from PHB400-50 to PHB1800-50. In the final region, the decrease of $\mathrm{E}^{\prime}$ can also be correlated to the gradual $\mathrm{T}_{\mathrm{m}}$ observed previously in DSC. 
Mechanical properties of the TPUs were further investigated by uniaxial tensile measurements Fig. 10 . displays the corresponding curves, while the data are summarized in Supporting Information (SI.7). Elastic moduli decreased significantly from 40 to $0.24 \mathrm{MPa}$ with the gradual addition of oligoPHB-diol moieties, as depicted in Fig. 10a. This decrease can be correlated to the diminution of crystalline regions due to the decreasing ISO content. This result is on agreement with results described in previous publications [[30](a), [34]]. A similar trend was obtained for the tensile strength at break, which is decreasing with gradual incorporation of oligoPHB-diol. As expected, despite the overall reduction of $\mathrm{DDI}$ and its flexible pending chains, when oligoPHB-diol content increased, elongation at break significantly extended until up to $840 \%$ for PHB450-75, due to an increased mobility of the chain and a crystallinity decrease.
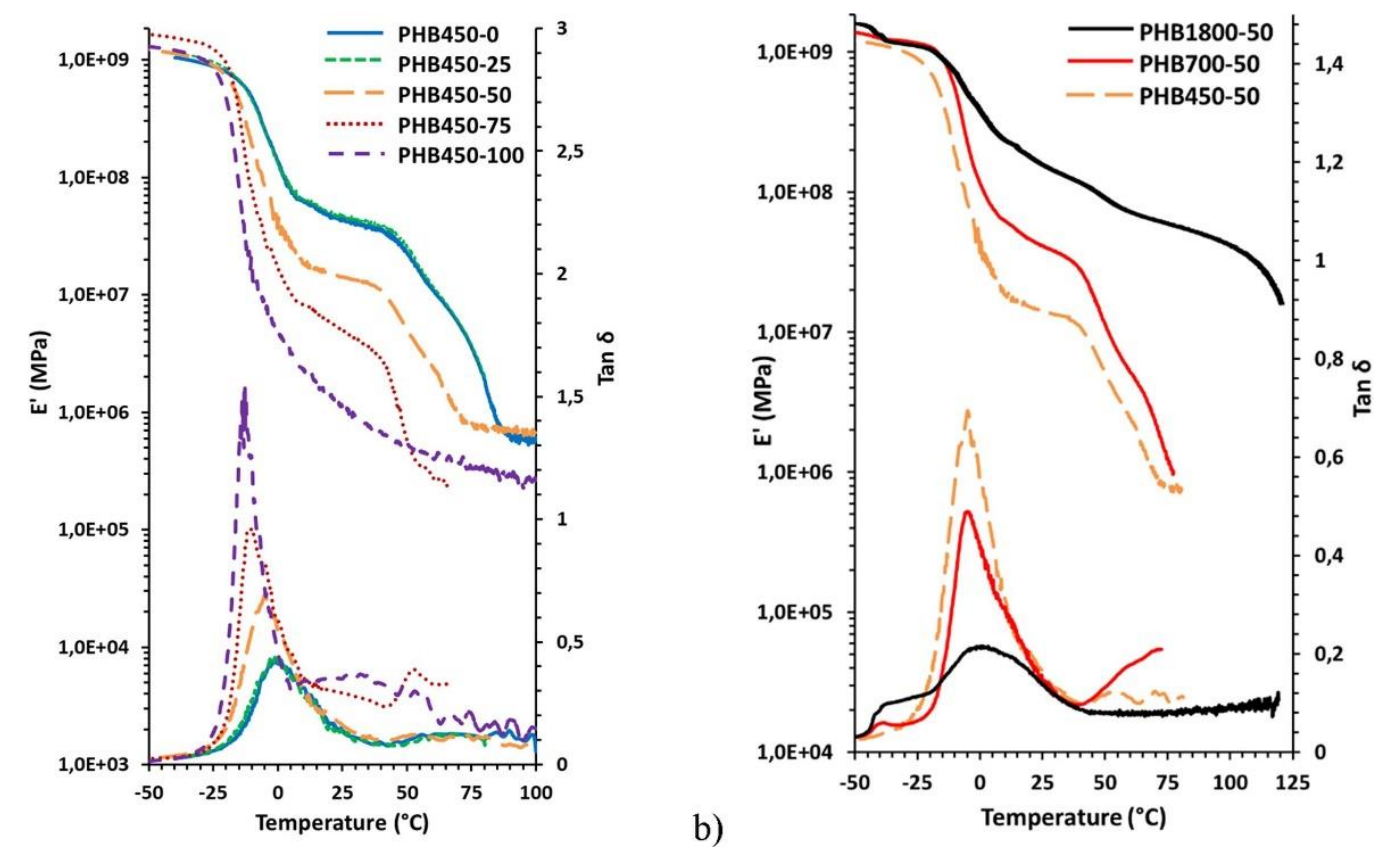

Fig. 9. Storage modulus $E^{\prime}$ (upper curves) and damping factor $\tan \delta$ (lower curves) with respect to temperature, for TPUs with a) increasing oligoPHB-diol content and b) different oligoPHB-diol $\mathrm{M}_{\mathrm{n}}$.

The overall shapes of the curves show different TPU behaviors depending on their formulations between a conventional thermoplastic with a yield point and a limited elastic region to a thermoplastic elastomer (TPE) with a high elongation at break and a low elastic modulus. PHB450-0, for instance, exhibited a typical rigid and tough material behavior with yield point due to high physical crosslink. It displayed a failure at $78 \%$ elongation. By incorporation of oligoPHB-diol (12.5 and $25 \mathrm{wt} \%$ ), higher elongations were promoted. However, these TPUs demonstrated plastic deformation and strain hardening after yield point, until reaching 195 and 179\% elongation and their break point, respectively. Finally, TPUs with greater amounts of oligoPHB-diol showed a typical elastic/rubbery mechanical behavior with high elongations as a TPE based on HS and SS segregations. A behavior largely found for TPU. During the experiments, no necking or drawing was observed despite PHB450-50, PHB450-25 and PHB450-0 presenting a certain level of crystallinity.

From the stress-strain curves of PHB1800-50, PHB700-50 and PHB450-50, exhibited in Fig. 10b, it can be deduced that increasing the molar mass of the oligo PHB building block increased outstandingly the elastic modulus and tensile strength of the corresponding TPUs. This was mostly due to higher physical crosslinks between esters and urethanes groups. This behavior is not surprising, since PHB is a highly crystalline, hard and brittle polyester. The higher the oligoPHB-diol molar mass, the closer its structure 
and behavior are from neat PHB. Like PHB450-0, PHB1800-50 exhibited a thermoset-like behavior with e.g., short elongation at break, with global moderate mechanical properties.
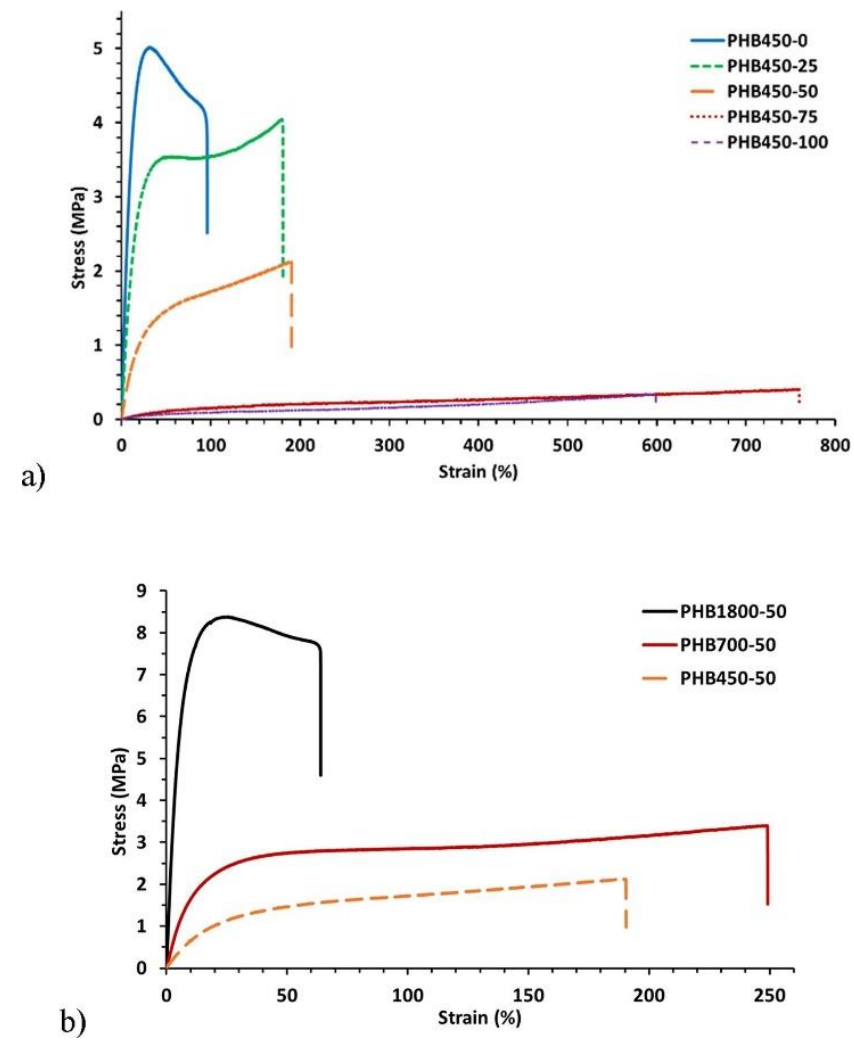

Fig. 10. Stress-strain curves for TPUs with a) increasing oligoPHB-diol content and b) increasing oligoPHB-diol Mn.

\section{Conclusions}

In this study, short oligoPHB-diols with controlled molar mass were successfully elaborated in a new green approach. This pathway is based on melt process without toxic or environmentally unfriendly solvent. Besides, the catalyst concentration was largely decreased compared to previous PHB-diol syntheses, in a greener approach. The reaction parameters were fully analyzed in order to obtain oligoPHB-diols with a controlled molar mass. The molar mass can be decrease until the equivalent of 3 repetitive units, no more. Finally, the parameters were optimized for a fast preparation of these bifunctional short molecules, which can be further used as a biobased platform building block for a large range of polymer synthesis. These short oligoPHB-diols with low molar masses were liquid-like with a low viscosity to further develop bulk polymerizations. Moreover, the excess of reactive solvent can be easily recycled on agreement with the principles for a green chemistry.

As a proof of concept, different fully biobased TPUs were further prepared to demonstrate the high potential of oligoPHB-diol as building blocks for the elaboration of thermoplastics with a large range of properties from conventional thermoplastics to TPE. The preparation of these fully biobased polymers is based on a one pot synthetic pathway with biobased DDI and varying ratios of ISO/ oligoPHB-diol ratios. The viscous behavior of low molar mass oligoPHB-diol allows a green synthesis without solvent and catalysts. The different synthesized TPUs exhibited a large range of physicochemical and mechanical properties, from strong and ductile to elastomeric behavior. Results differ from conventional biobased TPUs described in the literature, as the diisocyanate acts here as the major component of the SS domain. 
The wide range of properties allows various potential uses in many domains. These systems could for instance be useful as coatings or adhesives, but also as materials in packaging, automobile, building or for biomedical applications. Obviously, many other materials could be prepared from short chains oligoPHB-diols for new generations of biobased and biodegradable thermoplastics structures, such as polyesters and copolyester for instance. One could also imagine the valorization of these short molecules in crosslinked structures based on aromatic structures from e.g., tannins, lignins or furans.

\section{CRediT authorship contribution statement}

Sophie Wendels: Data curation, Conceptualization, Writing - original draft, Visualization, Writing review \& editing. Benoît Heinrich: . Bertrand Donnio: . Luc Avérous: Conceptualization, Methodology, Writing - review \& editing, Supervision, Validation.

\section{Declaration of Competing Interest}

The authors declare that they have no known competing financial interests or personal relationships that could have appeared to influence the work reported in this paper.

\section{Acknowledgement}

The authors are grateful to ANRT and Péters Surgical for their financial support with a CIFRE grant. We also want to thank Soprema for the use of tensile machine, and Dr. Khantutta-Kim Tremblay-Parrado for English corrections.

\section{Appendix A. Supplementary material}

Supplementary data to this article can be found online at https://doi. org/10.1016/j.eurpolymj.2021.110531.

\section{References}

[1] P. Furtwengler, R. Matadi Boumbimba, A. Sarbu, L. Averous, ACS Sustainable Chem. Eng. 6 (2018) 65776589.

[2] T. Debuissy, E. Pollet, L. Averous, ChemSusChem 11 (2018) 3836-3870.

[3] P.B.S. Albuquerque, C.B. Malafaia, Int. J. Biol. Macromol. 107 (2018) 615-625.

[4] E. Pollet, L. Averous, Biopolym.-New Mater. Sustain. Films Coatings (2011) 65-86.

[5] C. Utsunomia, K. Matsumoto, S. Taguchi, ACS Sustain. Chem. Eng. 5 (2017) 2360-2367.

[6] Z.A. Raza, S. Abid, I.M. Banat, Int. Biodeterior. Biodegrad. 126 (2018) 45-56.

[7] C. Kourmentza, J. Placido, N. Venetsaneas, A. Burniol-Figols, C. Varrone, H. N. Gavala, M.A.M. Reis, Bioengineering (Basel) 2017, 4.

[8] H. Abe, Macromol. Biosci. 6 (2006) 469-486. 
[9] N. Grassie, E.J. Murray, P.A. Holmes, Polym. Degrad. Stab. 6 (1984) 127-134.

[10] R. Renstad, S. Karlsson, A.-C. Albertsson, Polym. Degrad. Stab. 57 (1997) 331-338.

[11] (a) E. Hablot, P. Bordes, E. Pollet, L. Av'erous, Polym. Degradation Stability 93 (2008) 413-421; (b) P. Bordes, E. Hablot, E. Pollet, L. Averous, Polym. Degrad. Stab. 94 (2009) 789-796.

[12] M. Zhang, N.L. Thomas, Adv. Polym. Tech. 30 (2011) 67-79.

[13] M. Van den Oever, K. Molenveld, M. Zee, H. Bos, Bio-based and biodegradable plastics - Facts and Figures. Focus on food packaging in the Netherlands, 2017.

[14] E. Renard, D.-L. Versace, J. Babinot, V. Langlois, John Wiley \& Sons, Inc., 2015, pp. 150-172.

[15] Z. Li, J. Yang, X.J. Loh, NPG Asia Mater. 8 (2016).

[16] (a) M.P. Arrieta, J. L'opez, D. L'opez, J.M. Kenny, L. Peponi, Eur. Polym. J. 73 (2015) 433-446; (b) C. Mangeon, L. Michely, A. Rios de Anda, F. Thevenieau, E. Renard, V. Langlois, ACS Sustain. Chem. Eng. 6 (2018) 16160-16168.

[17] (a)T.D. Hirt, P. Neuenschwander, U.W. Suter, Macromol. Chem. Phys. 197 (1996) 1609-1614. (b)Z. `Spitalský, I. Lacík, E. Lathova, I. Janigova, I. Chodak, Polym. Degradation Stability 91 (2006) 856-861.

[18] J.O. Akindoyo, M.D.H. Beg, S. Ghazali, M.R. Islam, N. Jeyaratnam, A.R. Yuvaraj, RSC Adv. 6 (2016) 114453114482.

[19] (a) A. Arbenz, L. Averous, Green Chem. 17 (2015) 2626-2646; (b) S. Laurichesse, L. Averous, Progr. Polym. Sci. 39 (2014) 1266-1290.

[20] P. Furtwengler, L. Averous, Polym. Chem. 9 (2018) 4258-4287.

[21] Y. Li, B.A.J. Noordover, R.A.T.M. van Benthem, C.E. Koning, Eur. Polym. J. 59 (2014) 8-18.

[22] T.-M. Don, K.-H. Liao, J. Polym. Res. (2018) 25.

[23] (a) A. Granata, D.S. Argyropoulos, J. Agric. Food Chem. 43 (1995) 1538-1544; (b) A. Spyros, D.S. Argyropoulos, R.H. Marchessault, Macromolecules 30 (1997) 327-329.

[24] P.J. Barham, A. Keller, E.L. Otun, P.A. Holmes, J. Mater. Sci. 19 (1984) 2781-2794.

[25] T. Debuissy, E. Pollet, L. Averous, J. Polym. Sci., Part A: Polym. Chem. 55 (2017) 1949-1961.

[26] T. Calvo-Correas, M.D. Martin, A. Retegi, N. Gabilondo, M.A. Corcuera, A. Eceiza, ACS Sustain. Chem. Eng. 4 (2016) 5684-5692.

[27] B. Goderis, H. Reynaers, M.H.J. Koch, V.B.F. Mathot, J. Polym. Sci., Part B: Polym. Phys. 37 (1999) 17151738.

[28] M. Charlon, B. Heinrich, Y. Matter, E. Couzigne, B. Donnio, L. Averous, Eur. Polym. J. 61 (2014) 197-205.

[29] (a) D. Xue, X. Fan, Z. Zhang, W. Lv, J. Chem. 2016 (2016) 1-10; (b) S.H. Hsu, C.T. Hsieh, Y.M. Sun, J. Mater. Chem. B 3 (2015) 9089-9097.

[30] (a)C. Bueno-Ferrer, E. Hablot, M.d.C. Garrigos, S. Bocchini, L. Averous, A. Jimenez, Polym. Degradation Stability 97 (2012) 1964-1969. (b)I. Javni, Z. S. Petrovic, A. Guo, R. Fuller, J. Appl. Polym. Sci. 77 (2000) 17231734.

[31] Y. Li, B.A.J. Noordover, R.A.T.M. van Benthem, C.E. Koning, Eur. Polym. J. 52 (2014) 12-22.

[32] C. Bueno-Ferrer, E. Hablot, F. Perrin-Sarazin, M.C. Garrig'os, A. Jim'enez, L. Averous, Macromol. Mater. Eng. 297 (2012) 777-784. 
[33] K.P. Menard, N.R. Menard, Encyclopedia Polym. Sci. Technol. (2015) 1-33.

[34] S. Oprea, V.-O. Potolinca, V. Oprea, Eur. Polym. J. 83 (2016) 161-172. 